\title{
PROCESS CAPABILITY ASSESSMENT USING VISION SYSTEM
}

\author{
Shivanna Dodda Mallappa, Kiran Mysore Bhaskar, Venkatesh Gude Subbaraya, Kavitha \\ Shimoga Divakar
}

\author{
Department of Mechanical Engineering, School of Technology, Pandit Deendayal Energy University, \\ Gandhinagar, Gujarat, India
}

Corresponding author: Kiran M.B., MB.Kiran@sot.pdpu.ac.in

\begin{abstract}
Surface roughness assessment would help in predicting a component's functionality. This clearly shows the significance of measuring the surface roughness of machined components. Thus, each machined component, depending upon its intended function, requires a certain surface finish. To predict the surface roughness of a machined component, a detailed understanding of the machining parameters is essential. This is because, surface roughness generated on a component, depends upon machining parameters speed, feed, and depth of cut. A stable manufacturing process gives a consistent surface finish on all the manufactured components. Thus, only by having a stable process, consistent quality of manufactured products is possible. The capability of the machine is defined as the capability of the machine to carry out the set process efficiently and effectively to produce parts as per the specification limits. Machining parameters, tools, coolant flow rate, etc. An effort has been made in this research work, to show how by measuring surface roughness of machined components process capability can be assessed. Thus, the method is a novel technique of assessing the process capability of a given process. A capable process would help a manufacturing company in meeting customer expectations. The proposed method is of non-contact type, quick, and industry-friendly.
\end{abstract}

Key words: Surface Roughness Measurement, Process Capability Assessment, Process Capability, Capability Evaluation

\section{INTRODUCTION}

Surface roughness evaluation is significant in product manufacturing. Whitehouse [1] and Whitehouse and Archard [2], discuss the different types of filters used for separating roughness from waviness. Many researchers have worked on surface texture assessments [3, 4 and 5]. The texture is formed components such as form, waviness, and roughness. Many researchers have attempted to classify texture according to wavelength range- M-system [6] and Esystem [7] came into being. The filters are useful for separating the three components of texture, which is required for further analysis $[8,9]$.

In 1982, Whitehouse [10] proposed a simulation of M- system filtering mechanism. Research contributions of Whitehouse and Archard [11] are very significant. Up to 1960's researchers were using simple geometric shapes to model machining processes like turning and milling but were not of use while modeling grinding or polishing. Nayak [12] implemented random surface models while assessing surface roughness.

Surface roughness is a quality that has a direct impact on product performance and appearance [13]. Sajjad Ghodrati et al. [14] explored the significance of roughness assessments. The surface finish is difficult to define by a single parameter. Normally surface roughness is characterized by height parameter and wavelength parameter, reported by Inamdar [15]. Makiko Yonehara et al [16] did experiments to explore the effect of roughness on glossiness. In their experiments, they used polished and sandblasted surfaces. Thammarat Somthong and Qingping Yang [17] proposed a method for measuring the surface roughness of workpieces. The method makes use of imaging through stereo-method and coordinate measuring method (CMM).

The capability of the machine to carry out the set process efficiently and effectively to produce parts as per the specification limits. Machining capability would depend on its feed, speed, tools, coolant flow rate, etc. Many researchers [18-22] have focused on considerable theoretical and experimental research work for the betterment of both product quality and process capability (Cp) with the help of statistical techniques. The expression for machine capability is the same as the process capability. But it is denoted by $\mathrm{Cm}$ and the corrected machine capability is denoted by Cmk. In 1998, Deleryd defined process capability as - the ability of a manufacturing process to meet the customer's expectations [23]. Instead, problems have aroused due to a lack of knowledge in handling statistical data or misinterpreting it. Along with understanding the definition well, it is essential to know that, computing of $\mathrm{Cp}$ is based on two assumptions [24] and they are: (i) Quality characteristics under consideration follow a normal distribution. This assumption is made to have 
computational advantages. (ii) Process being studied is under statistical control. If a process is not under control, then $\mathrm{Cp}$ will fail in showing the capability of the process. The parameters, such as $\mathrm{Cp}, \mathrm{Cpk}$, and $\mathrm{Cpm}$, are extensively used in manufacturing processes to indicate to check product's compliance to specifications [25].

\section{METHODOLOGY AND EXPERIMENTATION}

Surface roughness is measured by using the steps given below.

1. Installation of charge-coupled device (CCD) camera onto the $\mathrm{CNC}$ milling machine: $\mathrm{CCD}$ camera is mounted on the work table to capture the surface image of the specimen being machined.

2. Mounting of the specimen onto the $\mathrm{CNC}$ machine: Specimen is fixed onto the work table to hold it for machining.

3. Setting up machining parameters to perform machining of the specimen.

4. Machining of the specimen: Specimens made out of aluminium, having dimensions $(8 \mathrm{~cm} \times 8 \mathrm{~cm})$, are machined, using BFW make vertical machining center, based on the machining parameters set (Table 1), using High-speed steel tool.

5. Monitoring Surface roughness parameters (Ra, Rq, $\mathrm{Rp}$ ): CCD camera captures the machined surface image, having a resolution of $512 \times 480$ pixels, while machining and calculating the surface roughness values. The system is calibrated by measuring known inputs. The device is used for measurement only after calibration.

6. Validation of roughness parameters by using stylus-based (contact) measuring method. Table 1 shows the roughness values obtained from both stylus and vision measurement methods. The stylus method is based on online sampling. Whereas, the Vision method is area-based. That is, the vision method computes the roughness parameters by using a window of $32 \times 32$ pixels.

Figure 1 shows the components of a vision systemframe grabber, CCD camera, advanced image processing card, and a MIL software development kit. Figure 2 shows the experimental set-up.

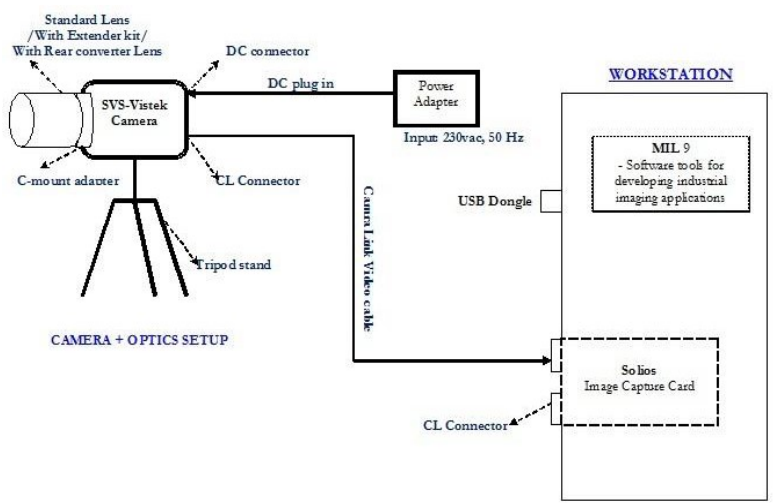

Fig. 1. Schematic of basic components of vision system

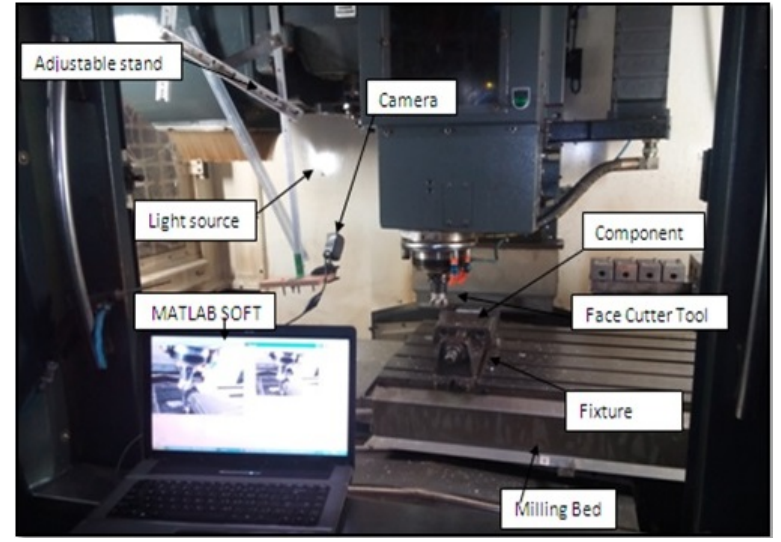

Fig. 2. Machine vision system setup attached with the milling machine

Mitutoyo- Surftest SJ-210 stylus instrument is used to evaluate the roughness for the specimens prepared by the milling process using different machining parameters. The surface roughness parameters are measured. These roughness parameters values for all the specimens are shown in Table 1.

The milling process is considered for the process capability experiment. The milled specimens are prepared by varying machining parameters are shown in Table 1. Surface roughness parameters are evaluated by employing the surface roughness tester (make: Mitutoyo, series: surftest-210). Table 1 shows the surface roughness values obtained through the profilometer for different specimens. The image of each specimen is captured using the CCD camera. The images are processed using MATLAB. The digital image is represented by a rectangular matrix with elements corresponding to the brightness. The basic image data is fed to the algorithms developed using MATLAB. Then vision system surface roughness $2 \mathrm{D}$ parameters are evaluated in MATLAB. The processing capability of the milling process is shown in Table 2.

\subsection{In Process Surface Roughness Evaluation}

Figure 2 shows the experimental setup for surface roughness evaluation by the in-process method. Machining parameters are varied for each specimen and machining is carried out in a CNC milling machine, images are captured using a computer vision system of the specimen being machined. These images are analyzed and quality of the image is improved and surface roughness parameters are measured.

Figure 3 shows details of different specimens. The image resolution is $512 \times 480$ pixels. Figure 3 shows the directions of the predominant surface pattern (lay). This is characteristic of a particular machining process. Milled specimens are characterized by lays shown in Figure 3. In the process measured surface roughness values are tabulated in Table 1 . 


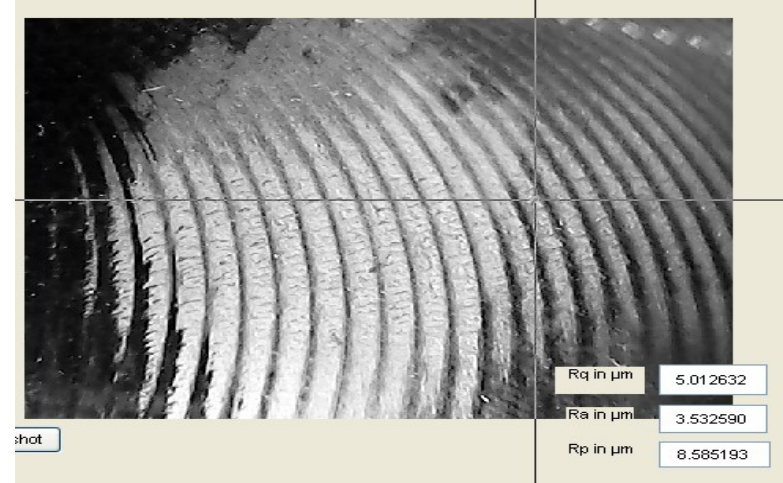

Specimen 1- Speed 300 revolution/minutes

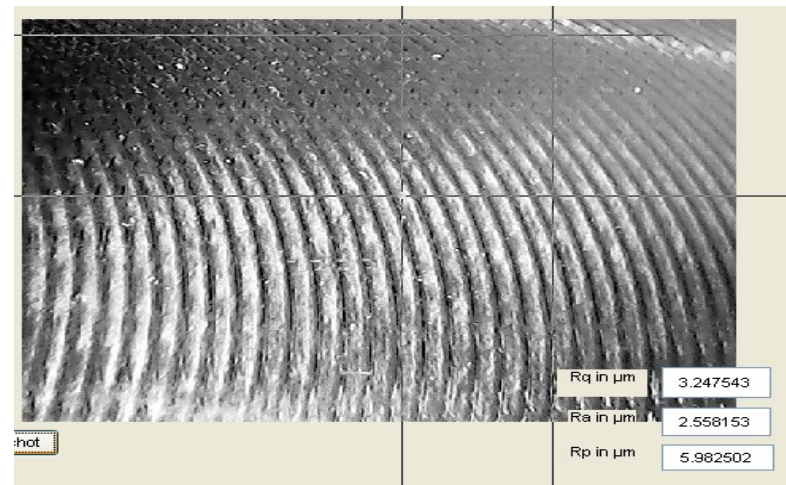

Specimen 2- Speed 400 revolution/minutes

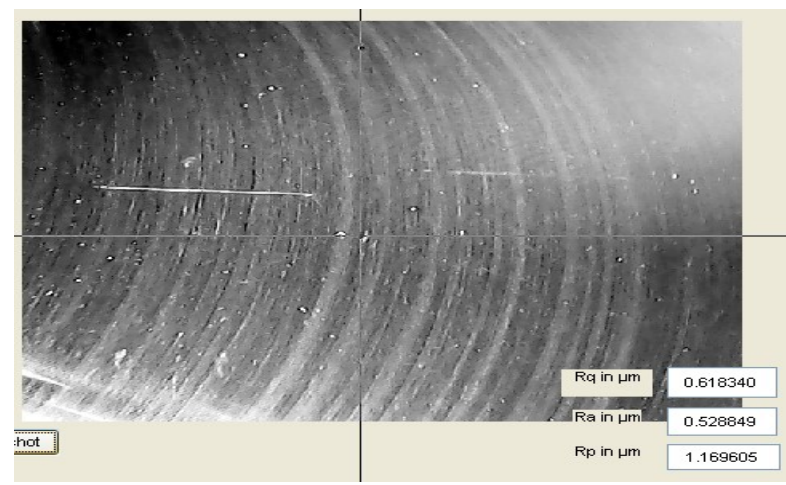

Specimen 3 - Feed 100 mm/minutes

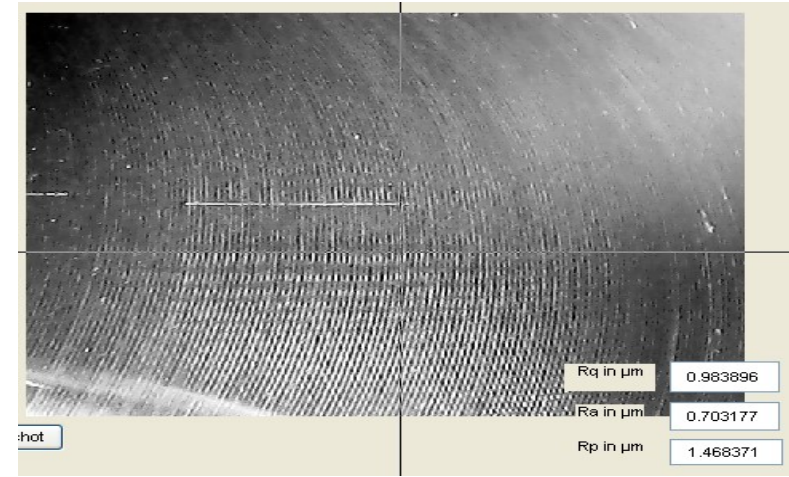

Specimen 4 - Feed 200 mm/minutes

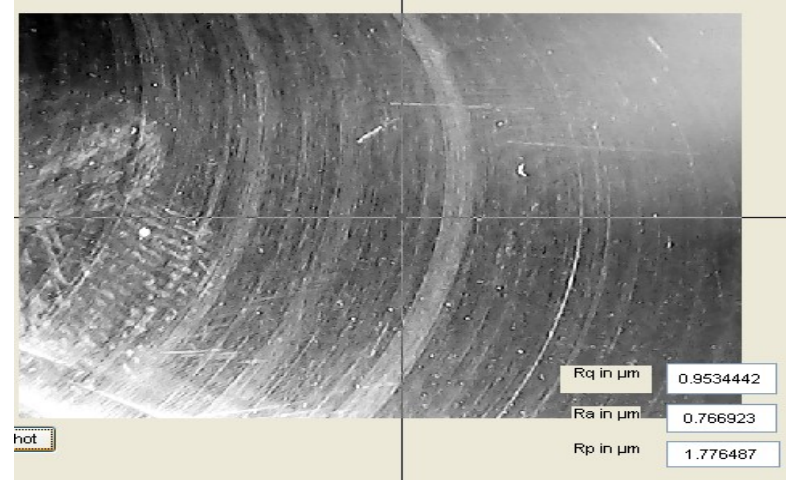

Specimen 5 - DOC 0.3 milli meter.

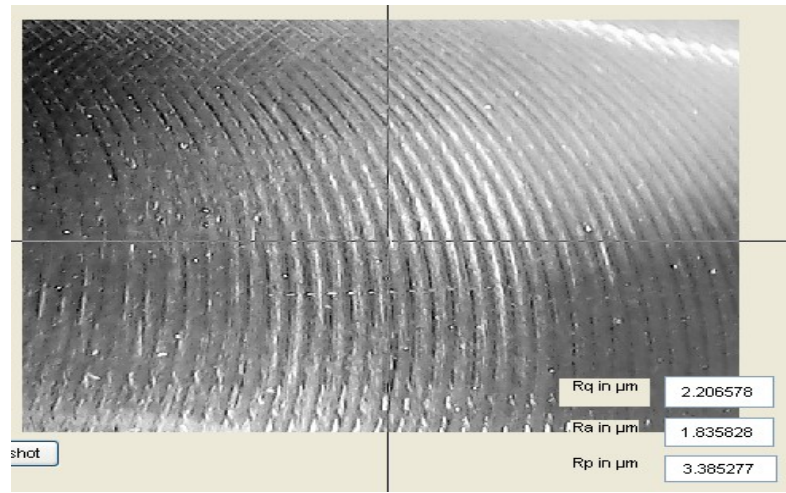

Specimen 6 - DOC 1 milli meter.

Fig. 3. Machined surface images along with surface roughness parameters

\subsection{Process capability evaluation}

The following steps are followed for evaluating the process capability:

1. Specimen preparation;

2. Roughness evaluation using vision system- Vision roughness parameter was measured for the different specimens. Table 1 shows the details.

3. Computing process capability. Table 2 shows the details of process capability.

\section{RESULTS AND DISCUSSION}

The experimental data obtained from the experiments conducted are analyzed and discussed. Machining parameters are varied for each specimen and machining is carried out in CNC milling machine, images are captured using a computer vision system of the specimen being processed. These images are analyzed and the quality of the image is improved by using filters and surface roughness parameters are measured. The processing capability of the milling process is analyzed by surface roughness of machined specimens. 
Table 1. Comparison of roughness values measured by stylus and proposed techniques

\begin{tabular}{|c|c|c|c|c|c|c|c|c|c|c|c|c|}
\hline $\begin{array}{c}\text { Sample } \\
\text { No. }\end{array}$ & $\begin{array}{c}\text { Speed } \\
\text { rpm }\end{array}$ & $\begin{array}{c}\text { Feed } \\
\mathrm{mm} / \\
\mathrm{min}\end{array}$ & $\begin{array}{c}\text { Depth } \\
\mathrm{mm}\end{array}$ & $\begin{array}{c}\text { Stylus } \\
\mathrm{Ra} \\
\mu \mathrm{m}\end{array}$ & $\begin{array}{c}\text { Vision } \\
\mathrm{Ra} \\
\mu \mathrm{m}\end{array}$ & $\begin{array}{c}\text { Error } \\
\%\end{array}$ & $\begin{array}{c}\text { Stylus } \\
\mathrm{Rq} \\
\mu \mathrm{m}\end{array}$ & $\begin{array}{c}\text { Vision } \\
\mathrm{Rq} \\
\mu \mathrm{m}\end{array}$ & $\begin{array}{c}\text { Error } \\
\%\end{array}$ & $\begin{array}{c}\text { Stylus } \\
\mathrm{Rp} \\
\mu \mathrm{m}\end{array}$ & $\begin{array}{c}\text { Vision } \\
\mathrm{Rp} \\
\mu \mathrm{m}\end{array}$ & $\begin{array}{c}\text { Error } \\
\%\end{array}$ \\
\hline 1 & 300 & 500 & 0.5 & 2.888 & 2.750 & 4.7 & 3.247 & 3.216 & 0.9 & 5.982 & 5.976 & 0.1 \\
\hline 2 & 400 & 500 & 0.5 & 2.558 & 2.423 & 2.4 & 2.918 & 2.733 & 6.3 & 5.892 & 5.706 & 3.1 \\
\hline 3 & 500 & 500 & 0.5 & 1.673 & 1.583 & 5.3 & 2.009 & 2.156 & 7.3 & 4.761 & 4.612 & 3.1 \\
\hline 4 & 1600 & 500 & 0.5 & 1.068 & 1.126 & 5.4 & 1.304 & 1.188 & 8.8 & 2.695 & 2.883 & 6.9 \\
\hline 5 & 1700 & 500 & 0.5 & 0.817 & 0.903 & 9.5 & 1.021 & 1.116 & 9.3 & 2.392 & 2.568 & 8.1 \\
\hline 6 & 1800 & 500 & 0.5 & 0.797 & 0.824 & 3.3 & 1.000 & 0.998 & 0.2 & 2.352 & 2.478 & 5.3 \\
\hline 7 & 3500 & 500 & 0.5 & 0.727 & 0.766 & 5.3 & 0.896 & 0.903 & 0.7 & 2.018 & 2.167 & 7.3 \\
\hline 8 & 3600 & 500 & 0.5 & 0.686 & 0.732 & 6.7 & 0.829 & 0.883 & 6.5 & 1.726 & 1.832 & 6.1 \\
\hline 9 & 3700 & 500 & 0.5 & 0.542 & 0.587 & 8.3 & 0.679 & 0.722 & 6.3 & 1.527 & 1.664 & 8.9 \\
\hline 10 & 1000 & 100 & 0.5 & 0.547 & 0.556 & 1.6 & 0.672 & 0.694 & 3.2 & 1.377 & 1.475 & 7.1 \\
\hline 11 & 1000 & 150 & 0.5 & 0.642 & 0.673 & 4.8 & 0.830 & 0.763 & 8.0 & 1.472 & 1.376 & 6.5 \\
\hline 12 & 1000 & 200 & 0.5 & 0.745 & 0.815 & 9.3 & 0.929 & 0.871 & 6.2 & 2.055 & 1.943 & 5.4 \\
\hline 13 & 1000 & 250 & 0.5 & 0.863 & 0.889 & 3.0 & 1.067 & 0.952 & 10.7 & 2.263 & 2.112 & 6.6 \\
\hline 14 & 1000 & 300 & 0.5 & 0.955 & 1.010 & 5.7 & 1.233 & 1.144 & 7.2 & 2.546 & 2.375 & 6.7 \\
\hline 15 & 1000 & 350 & 0.5 & 1.062 & 1.154 & 8.6 & 1.241 & 1.236 & 0.4 & 2.695 & 2.502 & 7.1 \\
\hline 16 & 1000 & 400 & 0.5 & 1.336 & 1.288 & 3.5 & 1.624 & 1.577 & 2.8 & 2.915 & 2.865 & 1.7 \\
\hline 17 & 1000 & 450 & 0.5 & 1.412 & 1.376 & 2.5 & 1.738 & 1.694 & 2.5 & 3.385 & 3.188 & 5.8 \\
\hline 18 & 1000 & 500 & 0.5 & 1.667 & 1.536 & 7.8 & 1.864 & 1.779 & 4.5 & 3.407 & 3.325 & 2.4 \\
\hline 19 & 1000 & 500 & 0.2 & 0.766 & 0.773 & 0.9 & 0.953 & 1.003 & 5.2 & 1.776 & 1.897 & 6.8 \\
\hline 20 & 1000 & 500 & 0.3 & 0.817 & 0.828 & 1.3 & 1.013 & 1.118 & 10.3 & 1.962 & 1.987 & 1.2 \\
\hline 21 & 1000 & 500 & 0.4 & 0.926 & 0.998 & 7.7 & 1.138 & 1.188 & 4.3 & 2.085 & 2.132 & 2.2 \\
\hline 22 & 1000 & 500 & 0.5 & 0.998 & 1.016 & 1.8 & 1.225 & 1.306 & 6.6 & 2.393 & 2.464 & 2.9 \\
\hline 23 & 1000 & 500 & 0.6 & 1.102 & 1.166 & 5.8 & 1.318 & 1.391 & 5.5 & 2.585 & 2.676 & 3.5 \\
\hline 24 & 1000 & 500 & 0.7 & 1.218 & 1.327 & 8.9 & 1.435 & 1.448 & 0.9 & 2.758 & 2.967 & 7.5 \\
\hline 25 & 1000 & 500 & 0.8 & 1.386 & 1.466 & 5.7 & 1.648 & 1.596 & 3.1 & 3.051 & 3.113 & 2.0 \\
\hline 26 & 1000 & 500 & 0.9 & 1.616 & 1.524 & 5.6 & 2.039 & 1.981 & 2.8 & 3.219 & 3.193 & 0.8 \\
\hline 27 & 1000 & 500 & 1 & 1.835 & 1.758 & 4.1 & 2.206 & 2.003 & 9.2 & 3.835 & 3.756 & 2.0 \\
\hline
\end{tabular}

Note: the stylus is stylus measurement and Vision is vision measurement

Table 2. Surface roughness parameters for milling, speed, feed, depth of cut, and vision system Ra with LCL and UCL

\begin{tabular}{|c|c|c|c|c|c|c|c|c|c|}
\hline $\begin{array}{l}\text { Sl. } \\
\text { No. }\end{array}$ & $\begin{array}{c}\text { Speed } \\
(\mathrm{rpm})\end{array}$ & $\begin{array}{l}\text { Feed } \\
(\mathrm{mm} \\
/ \mathrm{min})\end{array}$ & $\begin{array}{l}\text { DOC } \\
(\mathrm{mm})\end{array}$ & $\begin{array}{c}\text { Vision } \\
\text { system } \\
\text { Ra } \mu \mathrm{m}(\mathrm{Xi})\end{array}$ & $\begin{array}{c}\text { Vision } \\
\text { system } \\
\text { Ra } \mu \mathrm{m} \\
(\mathrm{Xi}, \text { Mean })\end{array}$ & $\begin{array}{c}\text { Vision } \\
\text { system } \\
\mathrm{Ra} \mu \mathrm{m} \\
\left(\mathrm{Xi}-\mathrm{X}_{\text {mean }}\right)\end{array}$ & $\begin{array}{c}\text { Vision } \\
\text { system } \\
\mathrm{Ra} \mu \mathrm{m} \\
\mathrm{Sq} .\left(\mathrm{Xi}-\mathrm{X}_{\text {mean }}\right)\end{array}$ & $\begin{array}{l}\mathrm{L} \\
\mathrm{C} \\
\mathrm{L}\end{array}$ & $\begin{array}{l}\mathrm{U} \\
\mathrm{C} \\
\mathrm{L}\end{array}$ \\
\hline 1 & 1000 & 500 & 0.5 & 1.435 & 1.3492 & 0.0858 & 0.0073 & 1 & 1.6 \\
\hline 2 & 1000 & 500 & 0.5 & 1.423 & 1.3492 & 0.0738 & 0.0054 & 1 & 1.6 \\
\hline 3 & 1000 & 500 & 0.5 & 1.513 & 1.3492 & 0.1638 & 0.0268 & 1 & 1.6 \\
\hline 4 & 1000 & 500 & 0.5 & 1.326 & 1.3492 & -0.0232 & 0.0005 & 1 & 1.6 \\
\hline 5 & 1000 & 500 & 0.5 & 1.128 & 1.3492 & -0.2212 & 0.0489 & 1 & 1.6 \\
\hline 6 & 1000 & 500 & 0.5 & 1.424 & 1.3492 & 0.0748 & 0.0055 & 1 & 1.6 \\
\hline 7 & 1000 & 500 & 0.5 & 1.393 & 1.3492 & 0.0438 & 0.0019 & 1 & 1.6 \\
\hline 8 & 1000 & 500 & 0.5 & 1.426 & 1.3492 & 0.0768 & 0.0058 & 1 & 1.6 \\
\hline 9 & 1000 & 500 & 0.5 & 1.397 & 1.3492 & 0.0478 & 0.0022 & 1 & 1.6 \\
\hline 10 & 1000 & 500 & 0.5 & 1.483 & 1.3492 & 0.1338 & 0.0179 & 1 & 1.6 \\
\hline 11 & 1000 & 500 & 0.5 & 1.364 & 1.3492 & 0.0148 & 0.0002 & 1 & 1.6 \\
\hline 12 & 1000 & 500 & 0.5 & 1.295 & 1.3492 & -0.0542 & 0.0029 & 1 & 1.6 \\
\hline 13 & 1000 & 500 & 0.5 & 1.129 & 1.3492 & -0.2202 & 0.0484 & 1 & 1.6 \\
\hline 14 & 1000 & 500 & 0.5 & 1.113 & 1.3492 & -0.2362 & 0.0557 & 1 & 1.6 \\
\hline 15 & 1000 & 500 & 0.5 & 1.354 & 1.3492 & 0.0048 & 0.0002 & 1 & 1.6 \\
\hline 16 & 1000 & 500 & 0.5 & 1.288 & 1.3492 & -0.0612 & 0.0037 & 1 & 1.6 \\
\hline 17 & 1000 & 500 & 0.5 & 1.376 & 1.3492 & 0.0268 & 0.0007 & 1 & 1.6 \\
\hline 18 & 1000 & 500 & 0.5 & 1.536 & 1.3492 & 0.1868 & 0.0348 & 1 & 1.6 \\
\hline 19 & 1000 & 500 & 0.5 & 1.423 & 1.3492 & 0.0738 & 0.0054 & 1 & 1.6 \\
\hline 20 & 1000 & 500 & 0.5 & 1.31 & 1.3492 & -0.0392 & 0.0015 & 1 & 1.6 \\
\hline
\end{tabular}




\begin{tabular}{|c|c|c|c|c|c|c|c|c|c|}
\hline $\begin{array}{l}\text { Sl. } \\
\text { No. }\end{array}$ & $\begin{array}{l}\text { Speed } \\
(\mathrm{rpm})\end{array}$ & $\begin{array}{l}\text { Feed } \\
(\mathrm{mm} \\
/ \mathrm{min})\end{array}$ & $\begin{array}{l}\text { DOC } \\
(\mathrm{mm})\end{array}$ & $\begin{array}{c}\text { Vision } \\
\text { system } \\
\text { Ra } \mu \mathrm{m}(\mathrm{Xi})\end{array}$ & $\begin{array}{c}\text { Vision } \\
\text { system } \\
\text { Ra } \mu \mathrm{m} \\
\text { (Xi, Mean) } \\
\end{array}$ & $\begin{array}{c}\text { Vision } \\
\text { system } \\
\text { Ra } \mu \mathrm{m} \\
\left(\mathrm{Xi}-\mathrm{X}_{\text {mean }}\right)\end{array}$ & $\begin{array}{c}\text { Vision } \\
\text { system } \\
\text { Ra } \mu \mathrm{m} \\
\text { Sq.(Xi-X } \\
\text { mean })\end{array}$ & $\begin{array}{l}\mathrm{L} \\
\mathrm{C} \\
\mathrm{L}\end{array}$ & $\begin{array}{l}\text { U } \\
\text { C } \\
\text { L }\end{array}$ \\
\hline 21 & 1000 & 500 & 0.5 & 1.186 & 1.3492 & -0.1632 & 0.0266 & 1 & 1.6 \\
\hline 22 & 1000 & 500 & 0.5 & 1.141 & 1.3492 & -0.2082 & 0.0433 & 1 & 1.6 \\
\hline 23 & 1000 & 500 & 0.5 & 1.366 & 1.3492 & 0.0168 & 0.0002 & 1 & 1.6 \\
\hline 24 & 1000 & 500 & 0.5 & 1.372 & 1.3492 & 0.0228 & 0.0005 & 1 & 1.6 \\
\hline 25 & 1000 & 500 & 0.5 & 1.366 & 1.3492 & 0.0168 & 0.0002 & 1 & 1.6 \\
\hline 26 & 1000 & 500 & 0.5 & 1.424 & 1.3492 & 0.0748 & 0.0055 & 1 & 1.6 \\
\hline 27 & 1000 & 500 & 0.5 & 1.438 & 1.3492 & 0.0888 & 0.0078 & 1 & 1.6 \\
\hline
\end{tabular}

Table 1 shows the machining parameters used while preparing milled specimens. Figures 5 and 6 show an excellent correlation in the roughness readings obtained from both vision and stylus methods. Thus, the vision method can be used for the roughness assessment of milled surfaces.

Excellent correlation between standard (stylus method) and the proposed method is obtained with a correlation coefficient of 0.98 .

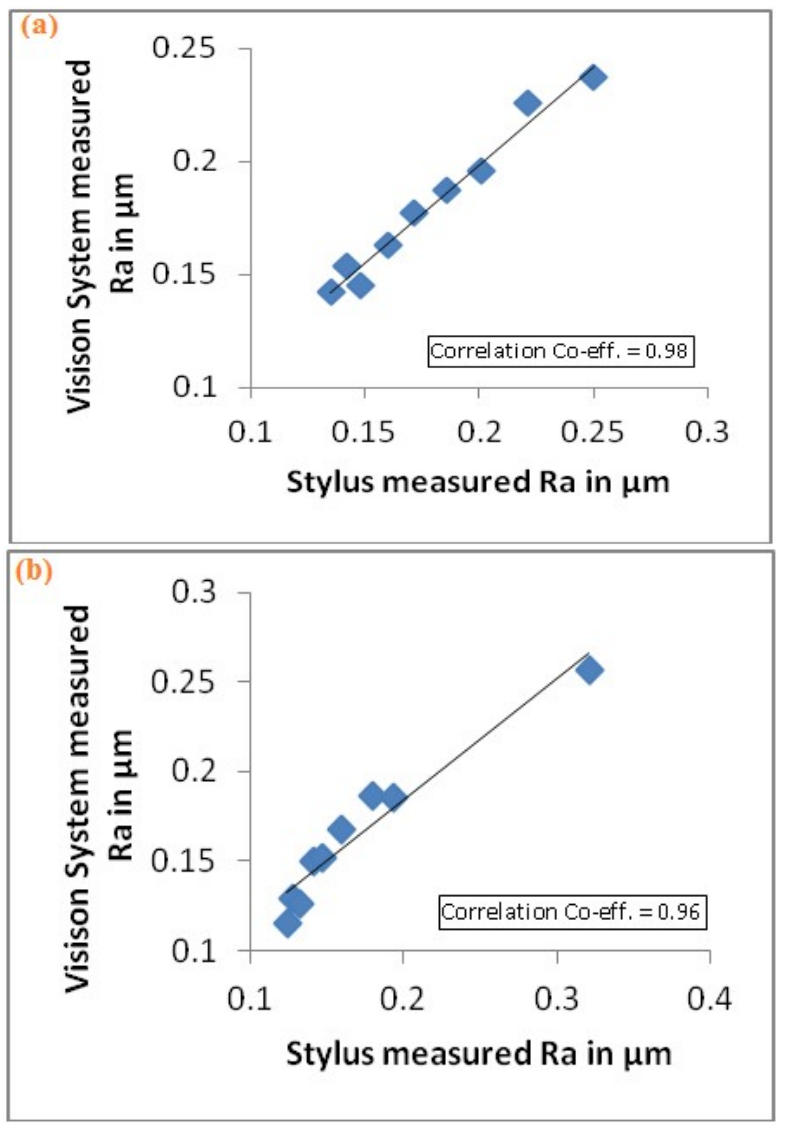

Fig. 5. Correlation curves at varying (a) speed (b) feed

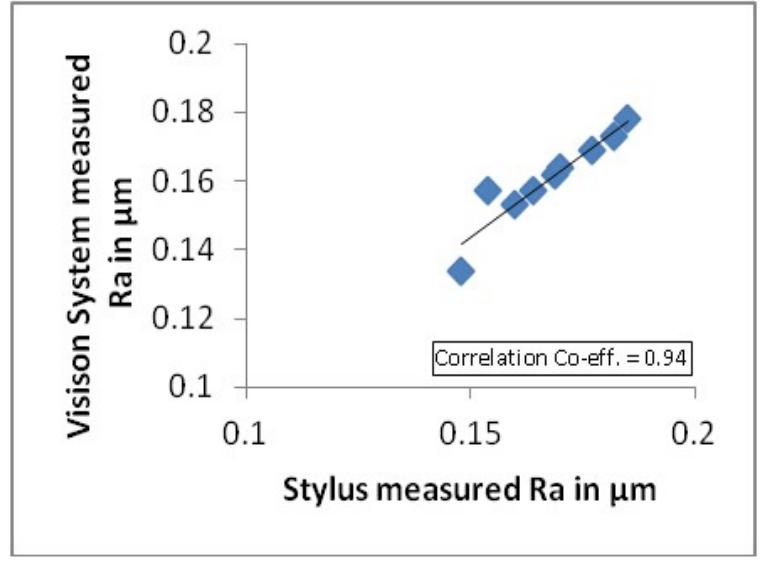

Fig. 6. Correlation curves at varying depth of cut

3.1. Graphical representation for Aluminum specimen for varying parameters

Figure 7 indicates a good correlation was obtained between the two methods within the speed range of 1800 to 3600 rpm. And correlation was not good for the specimens made outside this range. Figure 8 from these experimental results shown in the graph, surface roughness of the material is increased as feed increases. Figure 9 from these experimental results shown in the graph, surface roughness of the material is increased as the depth of cut increases.

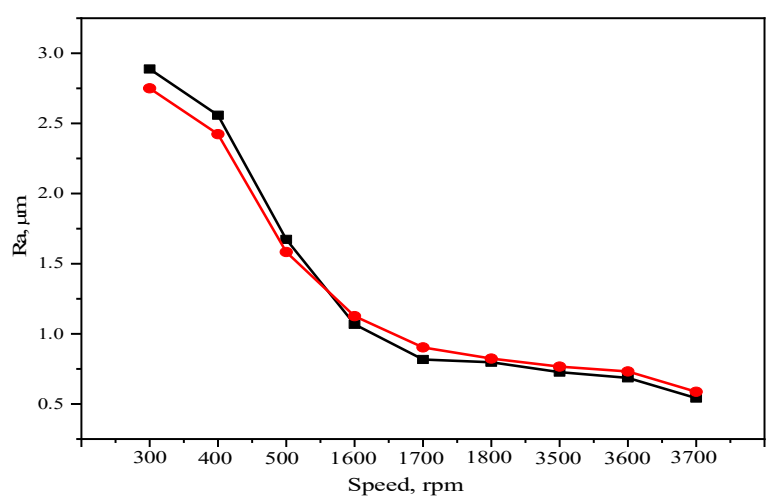

Fig. 7. Graph showing roughness values (stylus and vision system) measurements V/s varying speed 


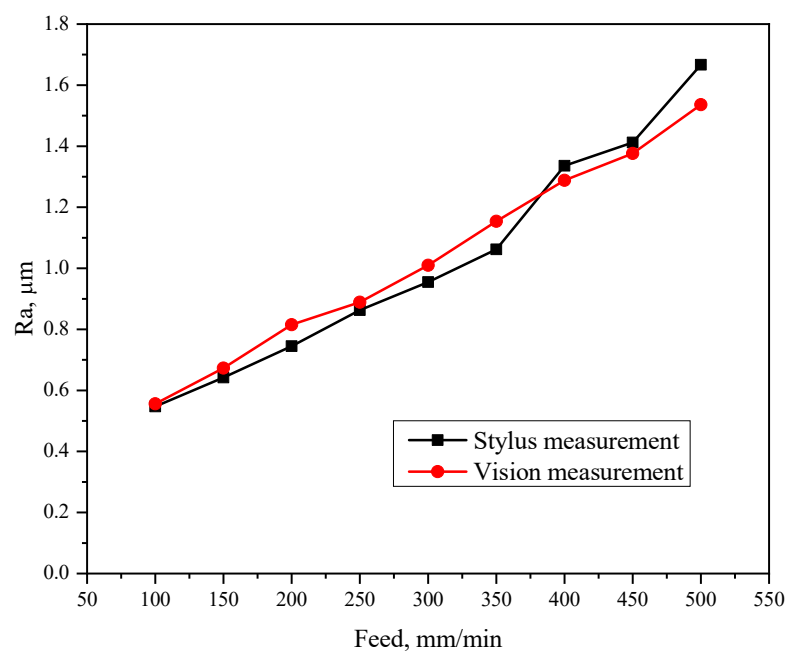

Fig. 8. Graph showing roughness values (stylus and vision system) measurements $\mathrm{V} / \mathrm{s}$ varying feed

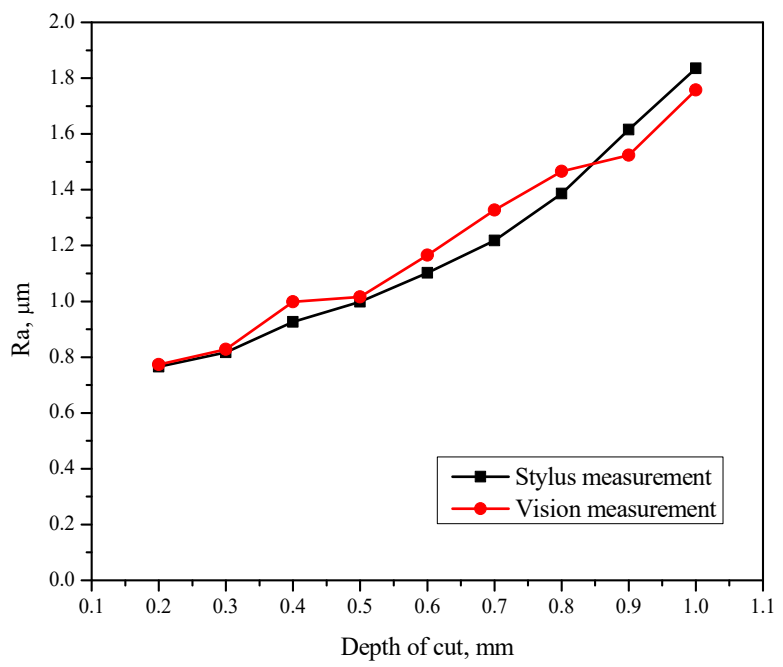

Fig. 9. Graphical representation of roughness values (stylus and vision system) measurements $\mathrm{V} / \mathrm{s}$ varying depth of cut

\subsection{Process capability}

The following paragraphs show the effect of machining parameters on the process capability of the milling process. Figure 10 represents the characteristic curves for process capability with varied process parameters.

Fig. 10 shows a relationship between vision surface roughness (Ra) and the number of samples in the region 1 to $1.57 \mu \mathrm{m}$. Thus, this method of milling process can be used for predicting the process capability within the specified region.

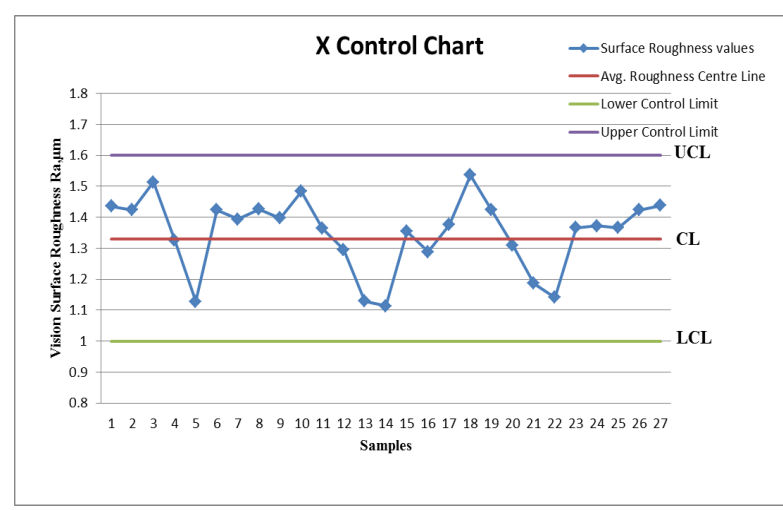

Fig. 10. Graphical representation of process variation as observed for machined samples wrt. varying speed, feed, and depth of cut

\section{CONCLUSIONS}

Present research work proposes a novel technique for determining the process capability of a manufactured process. The major advantage of the proposed method is that it is the non-contact way of measuring the process capability and is amenable for automation. Measuring process capability ensures manufacturing of the consistent quality product, for fulfilling customer expectations. For the research work, aluminium components were made by milling process on a CNC milling machine. The specimens are prepared by using different machining parameters. Roughness parameters were measured while performing milling, by fitting a camera sensor to the $\mathrm{CNC}$ Milling machine, connected to the vision system. C++ software developed in-house is used for computing surface roughness parameters. The maximum deviation between the two techniques is $9.5 \%, 10.7 \%$, and $8.1 \%$, for $\mathrm{Ra}, \mathrm{Rq}$, and $\mathrm{Rp}$ respectively.

Capability analysis helps in determining whether the manufactured component lies in between tolerance limits and engineering specifications. It was demonstrated from the current research that; surface roughness can be used for determining the process capability of a manufacturing process.

\section{REFERENCES}

1. Whitehouse D J (1994) Handbook of Surface Metrology, Institute of Physics Bristol.

2. Whitehouse, DJ, Archard, JF (1969) Properties of random processes of significance in their contact, ASME Contact Mechanics, Los Angeles: 36-57.

3. Kiran, MB, Ramakrishna $\mathrm{H}$, and Kuppahalli $\mathrm{P}$ (2012) A study on the evolution of surface roughness characterization, Manufacturing Technology Today: $11-16$.

4. Schlesinger, G (1942) Surface finish, Report of Research Department of Institute of Production 
Engineers, London.

5. Reason, RE (1944) Report on the measurement of surface finish by stylus methods, Leicester, UK: Rank Taylor Hobson.

6. Page, SF (1948) Fine surface finish. London, UK: Chapman and Hall.

7. Reason, RE (1961) Report on reference lines for roughness and roundness, CIRP Annals, Band XI, Heft 2 : 95-104.

8. Weingraber, H.Von (1967) The geometrical state of the surface of a solid, Proc. Int. Conf. Manufacturing Technology, 12: 71-84.

9]. Whitehouse, DJ (1982) The parameter rash is there a cure, Wear 83: 75-78 1982.

10. Whitehouse DJ, Archard JF, Proc. R. Soc. A 316971970.

11. Nayak, PR (1971) Random process model of rough surfaces. Trans. ASME 93, 398.

12. Sajjad Ghodrati, Saeideh Gorji Kandi and Mohsen Mohseni (2017) Roughness evaluation of randomly rough surfaces by non-contact image profilometry method, 7th International Color\& Coating Congress.

13. Inamdar, KH (2015) Various methodologies for assessment of surface quality, International Journal of Mechanical And Production Engineering, 3(8): 3740 .

14. Makiko Yonehara, Tsutomu Matsui, Koichiro Kihara, Hiroaki Isono, Akira Kijima and Toshio Sugibayashi (2004) Evaluation Method of Surface Texture by Surface Roughness based on Geometrical Product Specifications (GPS), Materials Transactions, Vol. 45, $4: 1019-1026$.

15. Thammarat Somthong and Qingping Yang (2016) Average surface roughness evaluation using 3-source photometric stereo technique, Int. J. Metrol. Qual. Eng. 7, 406: 1-10.

16. Jabnoun N (2002) Control processes for total quality management and quality assurance. Work Study; 51(4):182-90.

17. Ali Riza Motorcu and Abdulkadir Gullu (2006) Statistical process control in machining, a case study for machine tool capability and process capability, Materials and Design 27: 364-372.

18. Chaudhry SS, Higbie JR (1989) Practical implementation of statistical process control in a chemicals industry, Int J Qual Reliab Manage; 6:5.

19. Andrew A., Erameh, Nurudeen A. Raji, Rasheed O. Durojaye, Abiodun A. Yussouff, (2016) Process Capability Analysis of a Centre Lathe Turning Process, Engineering, 8: 79-85.

20. Xie M, Goh TN (1999) Statistical techniques for quality. TQM Mag; 11(4):238-42.

21. Deleryd M, Garvare R, Klefsjo B (1999) Experience of implementing statistical methods in small enterprises. TQM Mag; 11(5):341-51.

22. Ugur N, Caltug H (1995) Statistical methods on quality control, KOSGEB Education Centre, no. 25, Ankara.

23. Pearn WL, Lin PC, Chen KS (2002) Estimating process capability index $C^{\prime \prime}$ pmk for asymmetric tolerances: Distributional properties, Metrika, 54(3) 261-279.

24. Sachin Prakash Wanare, Mangesh V. Gudadhe (2013) Performance Analysis of Vertical Machining Center through Process Capability, International journal of innovations in Engineering and Technology, 2(2).

25. Aysun Sagbas (2009) Improving the process capability of a turning operation by the application of statistical techniques, MTAEC9, 43(1): 55-59.

Received: August 22, 2021 / Accepted: December 15, 2021 / Paper available online: December 20, 2021 (C) International Journal of Modern Manufacturing Technologies 